\title{
JUNTACADÁVERES DE JUAN CARLOS ONETTI: TANGO Y NOVELA
}

\author{
Frank Orduz Rodríguez \\ Universidad Pedagógica y Tecnológica de Colombia \\ Tunja, Colombia \\ frank.orduz.r@gmail.com
}

RESUMEN / ABSTRACT

\begin{abstract}
Este análisis es una aproximación a las relaciones entre la novela Juntacadáveres (1964) de Juan Carlos Onetti y el tango como fenómeno socio-histórico y artístico. Desde la construcción de un sujeto producto de los procesos de modernización en el Río de La Plata, Onetti compone un tipo de sujeto desencantado y escindido que contempla, siente y se relaciona con el mundo de forma semejante al sujeto del tango. Así, este análisis considera cómo el universo del tango permea las formas de la novela Juntacadáveres (axiología de los personajes, la construcción del espacio y la inserción y literaturización de algunas problemáticas históricas).
\end{abstract}

Palabras Clave: Juntacadáveres, tango, novela uruguaya contemporánea, Juan Carlos Onetti, historia del siglo XX.

\section{JunTACADÁveres BY JUAN CARLOS ONETTI: TANGO AND NOVEL}

This analysis is an approximation to the relations between the novel Juntacadáveres (1964) by Juan Carlos Onetti and the tango as socio-historical and artistic phenomenon. From the construction of a subject as a product from the modernization processes in the Rio de la Plata, Onetti creates a disenchanted and splinter subject that contemplates, feels and relates to the world in a similar way to the subject of tango. Thus, this analysis considers how the tango's universe permeates the forms of the novel Juntacadáveres (axiology of the characters, the construction of the space and the insertion and literaturization of some historical problems).

KEYWORDS: Juntacadáveres, tango, contemporary Uruguayan novel, Juan Carlos Onetti, 20th century history. 
¿Qué desencanto más hondo, qué desencanto brutal! ¡Qué ganas de echarse en el suelo y ponerse a llorar!

Cansao de ver la vida, que siempre se burla

y hace pedazos mi canto y mi fe.

("Desencanto" de Luis César Amadori y Enrique Santos Discépolo)

\section{INTRODUCCIÓN}

A pesar de ser la obra de Juan Carlos Onetti una de las propuestas literarias más concurridas por la crítica y estudios literarios de todas las latitudes, su relación con el tango parece ser un aspecto que al ser dado por hecho no ha recibido suficiente atención ${ }^{1}$. Su aire a tango es difícilmente objetado, pero no es solo su aire, es su relación vital con esta manifestación artística y cultural la que probablemente sostiene todo el universo de sus cuentos y novelas. La constante aparición del desencanto, el desarraigo y una especie de estoicismo que se conjuga con las espinosas circunstancias que viven los personajes de la obra onettiana tiene gran parte de su sustento en el universo que incubó una de las expresiones más autóctonas de la modernidad rioplatense y latinoamericana: el tango. Justamente en este escrito se analizará esta relación a partir de la lectura de Juntacadáveres (1974), novela del ciclo sanmariano, en donde ambiente y problemática aluden a aspectos de corte histórico, artístico y cultural del universo tanguero.

Siendo el tango una reacción al proceso represivo burgués y luego al de la modernización, este se erigió como una voz pre-moderna que señaló su

1 Aun así, hay trabajos que entre sus temáticas reconocen el vínculo entre Onetti, su narrativa y el tango. Este es el caso de Pablo Rocca (Prologador de las Obras Completas III), quien en la apertura del volumen III de las obras completas del escritor uruguayo indica que Onetti en su escritura recurre a registros orales del Plata que aparecen en innumerables tangos. Así también se puede referenciar el trabajo de Julio Premat, Cuando nombre, entonces relato (2003), quien anota que en Cuando entonces (1987) el tango es el telón de fondo de esta historia. 
descontento frente a los cambios traídos por las oleadas inmigratorias y los modelos europeos, instalados específicamente en La Plata. Carlos A. Gadea (2011) señala que el tango germinó acorralado en un contexto sociocultural marginal, producto de la inmigración que no solo originó una mezcla entre coterráneo con europeo, también originó unas formas particulares de vida, un lenguaje representativo y un código de convivencia, especialmente en las zonas periféricas. De tal forma surge un sujeto desencantado debido al nuevo ritmo impuesto por el mundo de la producción, el desplazamiento del campesino a la periferia, las nuevas formas del trabajo y la pérdida de los valores arraigados como la amistad y la palabra (72). Esto sumerge al ser marginal de La Plata en un ambiente donde el tango poco a poco -plantea Gadea- pierde su inocencia y se hace un contador enérgico de la situación de quien lo escucha (71).

Fue alrededor del tango que se dio una especie de contracultura encarnada en la figura del compadrito y de la milonguera, y se asentó en espacios como el cafetín, el prostíbulo, el conventillo, entre otros. Son estos sujetos y espacios los que transportan todos los valores que el tango canción proyecta en sus letras y a su vez advierten toda la complejidad y paroxismo de un momento de la historia de La Plata. Estos aspectos son los que aparecen a lo largo y ancho de los cuentos y novelas de Juan Carlos Onetti, pues detrás de un proxeneta, de una prostituta, de la meditación en la mesa de un bar o en la pensión se deja entrever una serie de guiños que formulan el contexto que gestó al tango como expresión social, política y cultural.

\section{DEL TANGO A LA NOVELA}

Antes de penetrar en el universo de Juntacadáveres y su relación con el tango, es pertinente hablar de la relación tango-novela en la literatura latinoamericana. Tal unión se ve con mayor esplendor en la literatura de la segunda mitad del siglo XX. Los autores, en su gran mayoría rioplatenses, concretaron sus propuestas estéticas desde algunos arquetipos tangueros, desde las mismas letras del tango o las problemáticas que se daban dentro del cosmos marginal que acunaban el tango como propuesta artística y contracultural.

Los compositores del tango echaron mano de los versos de poetas como García Lorca, citado en letras de tangos como "Milonga triste", de Homero Manzi. Lo mismo sucedió con Canción de otoño en primavera, de Rubén Dario, que aparece en "La novia Ausente", de Enrique Cadícamo, donde, 
introducidos por el sujeto lírico de la canción, se lee o escucha la cita explícita de los versos del autor nicaragüense. Este apunte refuerza la reciprocidad entre literatura y tango, pero es en la primera veintena del novecientos donde aparecen propuestas en la narrativa que comienzan a mencionar al tango y a hacerlo una herramienta de ambientación. Así es que se hace tendencia la inserción de las letras y de los personajes del tango. Propuestas como las de Ricardo Guiraldes, Roberto Arlt, Jorge Luis Borges², Manuel Puig y Adolfo Bioy Casares, entre otros, incursionan en el mundo del tango con gran éxito, elevando a la categoría de objeto estético el mundo del malevaje, del arrabal y del barrio.

Pero sin duda la relación entre tango y literatura, y en general la relación literatura y otros lenguajes artísticos, se acentúa en el momento en que el ímpetu de las vanguardias experimentales se atenúa y la novela aspira a una ficción más cercana a la realidad cotidiana. Fernando Aínsa (2000) resume que la novela latinoamericana se aleja, para la década de los sesenta, del esquema de ganadores y perdedores y se abre a “... la integración antropológica del rico acervo cultural del continente." (7). Tal cercanía se manifiesta en novelas como Boquitas pintadas de Manuel Puig y en gran parte de la obra de Pedro Orgambide (10), como parte de una cultura popular tanguera que se toma la literatura del Río de La Plata. También se cuentan novelas como El juguete rabioso (1926), de Arlt, Adán Buenosayres (1948), de Leopoldo Marechal, Diario de la guerra del cerdo (1969), de Bioy Casares, y varias novelas de Sábato como Sobre héroes y tumbas (1961) o El túnel (1948), en esta última donde el tango se convierte en un argumento de la realidad que presenta la novela (Motato 2011).

Luego, en otras latitudes del continente, aparecen propuestas como la de Manuel Mejía Vallejo y su Aire de tango (1973), novela que alrededor del mito de Carlos Gardel propone la historia de Jairo, joven idólatra "del Morocho del Abasto", que se configura como un alter ego de los sujetos de los tangos que escucha. La trama ambientada entre tangos, prostitutas y el ambiente de malevaje muestra la trasmutación de este mundo del tango en las zonas populares y marginales de Medellín, material literario con el que

2 Quien no solo irrumpe en el universo tanguero en sus poemas y relatos, también teoriza sobre este. Un ejemplo es la recopilación de cuatro conferencias sobre el tema en $E l$ tango (2016), trabajo citado en este análisis. 
Mejía Vallejo ahonda en el problema de la violencia urbana y el fanatismo, en un mundo hostil regido por el cuchillo, la muerte y el tango.

En este panorama, la literatura que maniobra sobre las aguas del tango, como de cualquier expresión de la cultura popular, se abre a la incorporación y literaturización de “... interpretaciones puntuales acerca de las complicidades, los aciertos o las injusticias surgidas entre grupos humanos que bien pueden ser cercanos, híbridos o incluso antagónicos. (Anaya López 2011, 176). En el caso de la inserción de las letras del tango o la usanza de la métrica tanguera, estos elementos no son meramente ornamentos, pues determinan el estilo de la obra, su contenido y su forma de lectura. En el caso de Juntacadáveres, el tango se manifiesta en la proyección de valores, sentimientos, transposiciones históricas y arquetipos que el tango modeló, aquellos mismos que surgieron del fenómeno inmigratorio y del advenimiento del proceso modernizante de finales del siglo XIX y principios del XX en el Río de la Plata.

\section{HACIA EL ALMA DE LAS PROFESIONES MARGINALES}

Juntacadáveres narra la historia de la llegada y caída del burdel de Larsen/ Junta/Juntacadáveres ante el poder político-religioso de la ciudad ficticia de Santa María. Larsen, el héroe proxeneta, desprecia la vida del trabajo burgués en el periódico sanmariano -El Liberal-y se zambulle en una empresa prostibularia que lo satisface. En su búsqueda de un prostíbulo de lujo, Larsen debe conformarse con una casa decrepita de prostitutas viejas y maltrechas, favorecido por el "aval" municipal concedido por el concejal y herborista Barthé. La fundación de la casa celeste en la costa conmueve a todos los habitantes de la temprana ciudad, genera odios y medios afectos que terminan en la expulsión de Larsen y sus prostitutas decrépitas. Es a través de la historia del burdel que Onetti crea un tejido social donde cada uno de los actores de esta ciudad participa, desde sus visiones particulares, de una identidad colectiva que modela valores imbricados en una realidad cultural e histórica.

Como primer encuentro con el tango, Juntacadáveres formula un universo sensible del canon socio-ocupacional marginal rioplatense del imaginario tanguero. Dado a que la literatura latinoamericana optó por romper el esquema de los grandes relatos y de heroicidades épicas, la sociedad del tango, como otros corpus populares, sus temas, sus móviles, pasiones y mitos, fueron un gran referente para obras como la de Onetti. En ese caso la aparición de la 
prostituta, el compadrito, la fauna política y la juventud desocupada, son el sustento humano desde el cual el autor uruguayo logra revalorar literariamente todos los valores que el tango transportó en sus letras, a la par que muestra situaciones muy cercanas a las del tango canción y a las de sus circunstancias de producción.

Pero este sustento humano no aparece como una mera sinécdoque de una profesión o como menciones ornamentales y pictóricas de una época. En la escritura de Onetti el encuentro con estos grupos humanos responde a la búsqueda del alma de una urbe que en su mayoría está construida por inmigrantes que ejercen profesiones y oficios de orden marginal. A diferencia de lo que se podría pensar de la elaboración literaria de estos sujetos, Onetti no se basa en la imagen generalizada para construir el carácter de la prostituta, el proxeneta y sus demás personajes. El autor uruguayo logra crear, a través de una escritura introspectiva, dramas individuales de corte universal, a la vez que reafirma que hay una sociedad rioplatense, real, mayoritaria, que siente a su manera la pasión de vivir como la desazón de perecer, pero sobre todo logra determinar esencias creadoras, vivas y nobles.

Además, el procedimiento formal que blande el autor de Juntacadáveres consiste en una suerte de transparencias históricas, donde a partir de caracteres literarios, comentarios y especulaciones de los personajes, se alude a un sujeto histórico, enraizado en un momento específico de la historia social, política y religiosa del Plata. Así, desde El pozo (1939) Onetti construye esta relación que Sonia Mattalia ha anotado como la ruptura con el criollismo o la novela de tono rural, “... respondiendo a la emergencia en el Plata de un amplio espectro urbano, cuyas aspiraciones y desilusiones como clase se desarrollan en las décadas del 20 y 30 , al tiempo que se distancia del experimentalismo vanguardista" (66). En tal sentido, es oportuna la tesis de Raúl Chavarri (1974), pues afirma que Juntacadáveres plantea toda una teoría de la profesión, donde Santa María, aparte de ser escenario, es una experiencia activa, en la cual el propósito de sus habitantes va ligado a todo un plan personal vocacional, ya sea de prostitutas o de proxenetas (531).

\section{LA PROSTITUTA}

Como reafirmación de la profesión, la novela inserta valores que se pueden encontrar en el tango, crea una relación vital, espiritual, entre el sujeto, su profesión y el mundo que lo rodea. Allí donde la idea generalizada confirma 
la inmoralidad de la prostituta, la rudeza del compadrito y la testarudez de la juventud, el tango configura la sensibilidad de la mujer que acamala, como la del hombre que sufre a solas y la de la juventud confundida por los cambios sociales y propios de la inexperiencia. Es así que la literatura toma de este mundo de canciones y de proyecciones sociales las formas de concretar la vida de los arrabales y de los sujetos que los andan.

La prostituta es uno de estos sujetos tangueros aprovechados por Onetti. El trabajo de María Bonita, Nelly e Irene, las mujeres que trae Larsen para la fundación de su prostíbulo en Santa María, pertenecen a un imaginario que Onetti conjura en una construcción de gran profundidad. Mientras que las valoraciones de los habitantes sanmarianos sobre las prostitutas estriban entre la vulgaridad y el morbo, adentro en la casa celeste, pero sobre todo dentro del alma de estas mujeres, otros deseos y sentimientos configuran su totalidad en una visión holística y desembarazada de moralidad.

Mientras para las últimas décadas del XIX la prostitución se erigía como uno de los problemas más álgidos de salud pública en La Plata, la prostituta adquiere un papel preponderante e inspirador para los letristas del tango. $\mathrm{Su}$ vocación de pacificadora de deseos sexuales trascendió al plano de lo emocional, de lo espiritual y de lo metafísico. El contraste que propone la novela de Onetti es evidente y es agudizado por las condiciones afectivas extremas en las que sitúa a las mujeres de la casa celeste.

En vista de que Onetti acude a toda una atmósfera expresionista ${ }^{3}$, su novela está plagada de un psicologismo descarnado, escondido en expresiones literarias que se acercan al orden de lo poético, aspecto esencial para mostrar la concentración de sentimientos como el repudio y la ternura. En este caso, las prostitutas son unas figuras negativas que en el tango y en la literatura pasan de ser mujeres fatales a mujeres heroicas y mártires. Un ejemplo de esta construcción tanto formal como simbólica es el paseo de Irene y Nelly por la rambla:

3 John F. Deredita (1973) observa esta cualidad desde su lectura de El astillero (1961). Allí destaca la configuración de un proceso vital de los personajes onettianos a partir de un decorado metafórico, que representa la disminución y subjetividad del ser en el mundo que presenta (662). En el caso de Juntacadáveres, y en general de todos los cuentos y novelas, se observan rostros despersonificados, cuerpos groseros y gestos incompletos que terminan por corresponder a una estética de lo grotesco, en el margen de un panorama que realza tales formas (un sistema espacial de orden naturalista y expresionista). 
Las caras llenas de pintura, manteniendo aún, ya fatigada, la doble expresión de humildad e indiferencia, se deslumbraban con los reflejos de la última luz de la tarde en los remos de los botes sobre el río, trataban de descubrir rasgos personales en los bustos con camisetas blancas que se movían, pequeños, sin mostrar el esfuerzo, a compás. (Onetti, Obras completas II 423).

Esta imagen trae consigo el trasfondo hostil del mundo al que se enfrentan las prostitutas. Al mismo tiempo el carácter de las prostitutas se muestra ablandado por una violencia moral que las hunde en el desprecio colectivo, a la vez que las arroja a la reafirmación de su culpa, en un ejercicio de autocondena. Esto es evidente también en la actitud de María Bonita con respecto al descanso y paseo por Santa María, pues la experiencia le ha dejado por sentado lo adverso que puede ser el mundo afuera (Onetti, Obras completas II 421-25). Esta misma situación se ve en otros pasajes de la novela y por consecuencia aparece el vínculo entre tango y novela, pues tanto obra como el universo tanguero muestran a la prostituta ya no como una mujer de instintos carnales y de la mala vida sino como "una pobre chica de barrio engañada" de esas de las que hablaba Carriego, de las que hablan las letras de los tangos (Savigliano 90), una mujer acusada y señalada: "Mala te llaman,/te acusan, te castigan,/y aquí sobre tu herida/la desesperación"4 (Manuel Barros, s.f.).

Por otro lado, la novela permite leer el rol protector que se le adjudica a la prostituta, a la mujer del tango, a la milonguera. En Juntacadáveres quien encarna esta situación es María Bonita, pues siendo la piedra angular del prostíbulo de Onetti, es también la solícita cuidadora del alma del proxeneta. Sus apariciones en la novela son determinantes en el desenlace de cada uno de los baches que se le presentan a Larsen, héroe proxeneta. Sus cualidades son la prudencia, la incondicionalidad y una imperturbabilidad ante la adversidad. "María Bonita era prudente e inmoral" (Onetti, Obras completas II 462), incondicional en la charla (480) y más en la escucha: "Hablame como si yo no estuviera. Si tenemos que cerrar, no importa; nos vamos a otro lado. Vos y yo podemos hacer muchas cosas" (485). Estas virtudes son muy cercanas a las que muestran letras de tangos como "Amiga" (1947) de Horacio Sanguinetti: 
Hoy que estoy viejo y enfermo

me regalas tu bondad

y te acercas a mi lado

para consolar mi mal.

Qué alegría me da verte, que placer oír tu voz;

al mirarte los recuerdos

me hablan de tu gran amor.

Fuiste amiga en horas buenas

y en las malas mucho más.

Y aunque en las letras del tango las mujeres también abandonan a sus hombres, no cabe duda de que son excepcionales compañeras y amigas, como bien lo dice la letra del tan reconocido tango "Mano a mano" (1923), de Celedonio Flores: "... hoy te evoco y veo que has sido/en mi pobre vida paria sólo una buena mujer. / Tu presencia de bacana puso calor en mi nido, / fuiste buena, consecuente, y yo sé que me has querido...". Claramente esta situación, esta idea de la mujer-prostituta cuidadora, leal e incondicional, es evidenciable en Juntacadáveres. Tales cualidades se conjugan con la sensibilidad que les proporciona Onetti a estos personajes, construyéndolas internamente como una especie de heroínas estoicas.

\section{EL PROXENETA}

Como uno de los héroes del canon moderno de la literatura, el proxeneta es un arquetipo tanguero que la propuesta literaria onettiana trabaja y expande, tanto en su faceta popular como en la existencial. Y son estas dos facetas las que se reúnen para concretar en ficción lo que la realidad parece mostrar por separado. En el caso del proxeneta, su actividad objetiva y sus deseos y axiología se desarrollan como dos formas que se reivindican una a la otra, a pesar de que cada una podría repelerse en el campo de las posibilidades morales y populares. Sin embargo, en el hombre del tango se puede avisar que la sublimación de ocupación y formas elevadas del pensamiento son una constante que en letras y novela aparecen como carácter fundamental del personaje.

Si bien la actividad prostibularia, el manejo y aprovechamiento de mujeres para complacer los deseos de otros, es desdeñable, lo que sucede en Juntacadáveres como en muchas letras del tango es que este hombre, 
este caferata, macró, cafiolo, entre tantos nombres, es un sujeto reflexivo $\mathrm{y}$ de una atención aguda ante su tiempo. Las estimaciones morales sobre su ocupación pasan a un segundo plano a pesar de que su trabajo es un eje problémico en la novela. Y pasa a un segundo plano porque en Larsen, más que fundar un prostíbulo, hay una vocación y voluntad de que su tarea sea perfecta, sea una obra que inspire la nobleza de cualquier actividad alentada por un principio estético ${ }^{5}$. En dadas circunstancias, la imposibilidad de esta empresa genera en el sujeto de la literatura onettiana una reflexión de los aspectos que la imposibilitan, proyectando en sus juicios puntos universales como el paso del tiempo, la fragilidad humana, la incertidumbre, la maldad, el amor, la corrupción y la esperanza.

En los tangos el proxeneta es retratado como un vividor, seductor, despreocupado e inmoral, la estampa más externa de Larsen, aquella imagen grotesca que como método de defensa intenta alimentar el personaje ante la visita de médico Díaz Grey (Onetti, Obras completas II, 390-91). Tangos como El porteñito (1903), de Villoro, hace una alusión explicita a este carácter del proxeneta al cantar: "No hay ninguno que me iguale/para enamorar mujeres,/ puro hablar de pareceres,/puro filo y nada más./Y al hacerle la encarada/la fileo de cuerpo entero/asegurando el puchero/con el vento que dará." (Del Priore 2011). Sin embargo, tal presentación de este arquetipo tanguero es apenas la punta del iceberg, pues su dilema existencial radica en su problema vocacional, el de ¿cómo llegar a aquella hipotética muchacha nacida para el destino de su burdel? (Onetti, Obras completas II, 514).

En ese dilema, del que es presa Larsen/Junta, afloran una serie de sentimientos que Sábato (2005) anota como propios de compadrito: "Tiene, en suma, ese descontento, ese malhumor, esa vaga acritud, esa indefinida y latente bronca contra todo y contra todos que es casi la quintaesencia esencia del argentino promedio." (19). Y acudimos a la estampa del compadrito porque hay algo de Larsen en él, como en los demás personajes de la novela, desde la delicadeza al trato, su constante pie de guerra, sus cualidades para la botella (Gobello 14-16), hasta ese carácter meditativo sobre el paso del

\footnotetext{
Hugo Verani en su artículo Un diálogo de artistas fracasados: Juntacadáveres (1980), muestra que en la narrativa del autor uruguayo hay una relación entre la condición del hombre y la del artista. Esta idea es clara y el crítico la resume al decir que en Juntacadáveres, en cada una de las historias de los personajes que componen la novela, reside la necesidad vital de llenar de sentido sus empresas, en un afán de perfección y singularidad, por más humildes o ruines que sean sus proyectos.
} 
tiempo y su atribulada vida, aspectos que Sábato apunta como fundamentales de la poética tanguera (27-31).

\section{EL COMPADRE COMO PARADIGMA ONETTIANO}

Y si fuera por hacer un rápido inventario sobre los intertextos tangueros que la novela usa en su composición, no cabe duda de que la presencia del carácter del compadrito en cada uno de los hombres de la novela es ineludible. Desde la inseguridad del joven Malabia, hasta el ímpetu de pelea de Marcos Begner, el carácter del compadrito se cuela entre maneras y palabras de cada uno de los personajes. Pero lo primero a resaltar es que en el compadrito onettiano hay una cualidad elevada que, sin ser mostrada de forma abarrotada y presuntuosa, identifica su problema metafísico de ese abandono prematuro de la eternidad, del que habla Sábato $(2005,28)$. Es ese mismo sujeto al que hace referencia Borges en El Tango (2016), ese que con estoicismo, a portas de una operación sin anestesia, le dice al médico Casares: "Del dolor me encargo yo" (50).

El compadrito, como un arquetipo de la tradición literaria rioplatense, es propuesto por Borges como un sujeto que se propuso el ideal de ser valiente, desde una exaltación casi heroico-mitológica. Contrario a esto, los sujetos de Onetti poseen una valentía que se avista en los escenarios más insignes del tango, pero en situaciones más cotidianas que los grandes encuentros a cuchillo. Tanto hombres como mujeres defienden su causa y la trabajan día a día. Mientras Borges crea una mitología del compadrito y del cuchillo, Onetti lo baja del Olimpo cuchillero al barrio y revalora su reflexión en su relación con su entorno proteico. El paradigma del compadrito de Onetti es el interior, el que toma decisiones de tonalidades estoicas: caminar por las calles prejuiciosas (Onetti, Obras completas II, 421-25), la opción de la soledad, como Díaz Grey; o la búsqueda de empresas en espacios adversos, como Larsen. Y sin embargo, Onetti acude a la virtud del compadrito y a su estampa prototípica que en varios renglones de Juntacadáveres reitera: “el sombrero contra la ceja derecha, la gran moña negra de la corbata deslizando sus puntas bajo el cuello” (410), “(...) los zapatos de charol con cintas anchas, 
pesadas" (461). Así, tanto una de las facetas interiores del compadrito como la "pinta" gardeliana ${ }^{6}$ se concentran en Juntacadáveres.

En Juntacadáveres, el compadrito deja de tener ese carácter despectivo, y si al caso pueril, ya que su construcción tiende a rasgos más psicológicos, mediados literariamente por las prácticas de los personajes. Su relación introvertida con el espacio y los demás sujetos de la obra, su pensar, su sentir, justifican el drama interior del que habla Sábato. Marcos Begner, que podría ser el sujeto con mayores visos externos del compadrito, tiene en su bronca diaria, en su borrachera constante, una necesidad de mantener su estado, como producto de sus circunstancias, de esa "alta casuística" de la que habla el personaje mismo (Onetti, Obras completas II, 555). Su confusa bronca contra todo, quintaesencia del compadrito y del argentino, según Sábato, en Marcos Bergner se avista y la generan los aspectos que marcan la existencia histórica de Santa María: la inmigración y la prostitución. A su vez las contradicciones de este personaje son resultado, según los datos de la narración, de una fijación por el deber divino y patriótico que se mezcla con la concupiscencia y sus manías violentas. Incluso hay grandes marcas de ironía que refuerzan sus contradicciones: "Tengo que matar a alguien. La raza es patria; y yo no soy gringo, no soy alemán, no soy suizo" (532), a pesar de su marcada línea de sangre trasatlántica, evidente en su apellido. A esto hay que sumarle su odio a sí mismo y su paranoia: "Quedó definitivamente despierto, a la defensiva, odiándose por estar vivo y lúcido, entumecido por el odio como por un dolor" (529-30).

\section{UN TIEMPO HOSTIL Y UN PENSAMIENTO TRISTE QUE SE ESCRIBE}

Onetti, desde una escritura con visos expresionistas, hace que sus personajes emitan ciertas posiciones que guardan correspondencias con algunas letras del tango. Y aunque el intertexto en las novelas de Onetti es sumamente vasto, sí se pueden encontrar ideas y sentires propios de la temática tanguera, incluso monólogos pausados, similares a algunas letras de tango. Una muestra de este encuentro entre música y literatura es una de las meditaciones de Díaz Grey, muy similar a las del tango "Nadie" (s.f.) de Evaristo Fratantoni. 
Saber quién soy. Nada, cero, una compañía irrevocable, una presencia para los demás. Para mí nada. Cuarenta años vida perdida. (Onetti. 2007 438)

\author{
Con la cabeza gacha \\ y hundido tras las sombras \\ oscuras de un fracaso \\ aquí me pueden ver. \\ Cual cosa que no importa, \\ pequeña y que no cuenta, \\ de quien pudo ser algo \\ y poco o nada fue... (Fratantoni)
}

Y es que la historia de Santa María está atravesada por el tango, ya sea porque su ambiente y algunas situaciones en Juntacadáveres tienen grandes coincidencias con la historia social de este fenómeno cultural, o bien por los sentimientos que transporta en sus letras. Esto se advierte porque en las letras de estas canciones se puede ver aquello que sucede en la temprana ciudad de los sanmarianos, como por ejemplo en Así es el tango, de Homero Manzi, cantan: "El amor/del rancho o de chalet"; la "tristeza de arrabal/y rencor/ de horario y de jornal", así como aquel sinsabor del que habla Sábato, esa "Desazón/de llorar lo que fue/y mirar lo que llegó/sin poderlo comprender".

En dado caso el componente histórico también tiene protagonismo en la literatura onettiana, si se reconsidera que la historia del Plata ha sido contada por las letras del tango y que Onetti, siendo uno de los precursores de esa literatura sobre el sujeto suburbano y urbano, muestra ese sincretismo entre música y literatura. Así, el diálogo que propone Onetti con la historia es de facto el soporte y argumento que da a su propuesta estética ese carácter antropológico popular que marcó la entrada de la literatura latinoamericana a la modernidad, sustentado en lo que llamaba Ángel Rama el repertorio latinoamericano (1973).

Para hacer una referencia de los elementos históricos que usa el autor de Juntacadáveres, la novela enlaza todo dato histórico, intertextual, con la vida de Santa María, pueblo ficticio. Es así que la ciudad de Juntacadáveres no solo adquiere un carácter verosímil, por los hechos remembrados, sino un carácter vital al dotarla de un pasado que justifica su presente. Por eso es que las evocaciones de los personajes conectan a Santa María con algunos acontecimientos de los procesos de acentuación de la actividad prostibularia, sus comienzos y su organización en La Plata. Estos aspectos dan razón de ser a personajes y situaciones en la novela. En consecuencia, es necesario apuntar algunos de estos sucesos históricos alrededor del tango que se encuentran en el tejido de Juntacadáveres. 
El primero concierne al inicio de la actividad prostibularia en la Colonia Suiza. Con una referencia explícita sobre los inicios de los primeros visos de prostitución en La Plata, Onetti logra darle cuerpo, en la voz de Díaz Grey, al embrión de la prostitución en Santa María. Así como en La Plata, la narración del médico concuerda con la de historiadores del tango como Carretero, quien contextualiza en su trabajo Tango: testigo social (1999) las circunstancias en las que se dio el tango. Precisamente Onetti hace toda una alusión en su novela a ese universo que formó al tango, a la vez que inserta problemáticas de este cosmos. Así, luego de la llegada de los inmigrantes a la Colonia Suiza (Onetti, Obras completas II, 474), sugerencia breve al fenómeno inmigratorio, Díaz Grey menciona cómo comenzaron en Villa Petrus a construirse las primeras casas de descanso y encuentros amorosos, primero con chinitas y luego con mujeres de la misma clase (561) a la que pertenecían los extranjeros.

Esta aclaración sobre las mujeres deja un aspecto a la luz, la categoría de los burdeles, su procedencia, sus trabajadoras y sus status. Carretero (1999) consigna en su trabajo que hacia 1870 se diferenciaban los prostíbulos entre los de lujo y los demás. Los primeros eran de alto costo, a donde solo asistía gente adinerada. Ubicados en la calle Defensa eran muy bien amoblados, con variedad de atracciones, juegos y diversidad de atractivas y jóvenes mujeres para la elección de cualquiera, ellas, alemanas, italianas, francesas, etc. Por el contrario, estaban los prostíbulos pobres, de casas decrepitas y de mujeres viejas, negras, mulatas, indias y raramente una que otra blanca. Allí frecuentaban marineros obreros, criollos e inmigrantes (30).

Así que Larsen se debate entre lo que desea y lo que tiene: entre el prostíbulo de lujo y su prostíbulo de medio pelo. Esto trae consigo la característica principal de su prostíbulo pobre: el de mujeres viejas y "mal conservadas", María Bonita "envejecida" (Onetti, Obras completas II, 420), Irene "la gorda" (422) y Nelly, "la rubia gordita" (546), mujeres "feas y envejecidas" (363). Al mismo tiempo salta a la vista otro aspecto que tiene que ver con el status del prostíbulo: el concerniente con el de la persona encargada de este negocio. Según Carretero (1999), en la Argentina los prostíbulos de mejor categoría, según los registros de control sanitario y administrativos, eran dirigidos por mujeres de nacionalidad europea, de edades superiores a los 45 años, que eran llamadas "madamas" (35). Esta situación es parodiada por tangos como "Muñeca brava" (1929) de Enrique Cadícamo, que en sus versos muestra a la mujer que se hace la fina con modos afrancesados. Onetti también hace parodia de estos aspectos, pues en el caso de la Tora muestra a la administradora del 
prostíbulo con ínfulas de exquisitez, que focaliza en sus maneras y en sus "erres" marcadas al hablar (Onetti, Obras completas II, 413-15).

Otro aspecto de orden histórico y tanguero que aparece en la novela de Onetti es el trato entre políticos y proxenetas. El encuentro entre Larsen y el boticario y concejal Brathé no es meramente instrumental para representar el choque de intereses que en las relaciones humanas es tan común. Además de proporcionar un marco típico de la corrupción del poder político, el encuentro entre estos dos roles se remonta a las relaciones que, en tiempos del tango, finales del XIX y principios del XX, sostenían estos sujetos en las contiendas políticas, en las concesiones administrativas y, en general, en cualquier situación donde el uno pudiera sacar provecho del otro. El contexto no dejaba de ser complejo: ante la llegada de los inmigrantes, la gran cantidad de hombres que arribaron al Plata, la disparidad entre el número de hombres y mujeres y las costumbres extranjeras, la prostitución se abrió paso, así como los primeros visos de su reglamentación. Ante esto, los políticos, encargados de dicha reglamentación encontraron en los proxenetas, compadritos o malevos, figuras de acción que estaban dispuestos a hacer el trabajo sucio (Carretero 1999):

\begin{abstract}
Ambos se necesitaban y complementaban como caras de una misma moneda: el político necesitaba a los hombres de acción para ganar las elecciones. Estos, por su parte, a cambio de su trabajo, necesitaban la protección del político para hacer a un lado los sumarios, cuando incurrían en delitos, aceptando sus actividades prostibularias como cualquier actividad de trabajo legítimo (46).
\end{abstract}

Este tema de corrupción, visto en las mismas letras del tango, Onetti lo ubica como uno de los tantos vicios de esta sociedad sanmariana. La relación entre el concejal y Larsen es simbiótica y es un eje transversal entre la ficción y la realidad. Así, la novela muestra la intervención de Barthé ante el consejo para la fundación del burdel de Larsen en Santa María, que a su vez está supeditada por la votación del consejo sobre la concesión de los changadores del puerto. Además, los frutos de esta asociación son estipulados por el mismo concejal “(...)-Mantengo las mismas condiciones (...) Sólo quiero quinientos pesos por mes para ayudar a los gastos del semanario" (Onetti, Obras completas II, 409). Pero este escenario trasciende los renglones de la historia y la literatura. El tango canción, como línea de los planteamientos de este análisis, aparece con grandes reflejos de su intelecto popular para entender y reflejar esta situación. En este caso aparecen letristas como Luis Torres García con su tango "El corrupto" (s.f.): "Corrupto,/cara dura y 
chamullento./La guita es tu único interés./Pitutos, influencias y presiones/ que transformas en millones,/sin poderte contener".

$\mathrm{Y}$ entre tratos y artimañas, en Juntacadáveres hay más situaciones de corrupción que tangos, historia y la misma novela recrean desde sus propios registros y aportan una mirada particular de los mismos hechos. Por eso es que en el discurso y línea de los personajes de Juntacadáveres aparecen valoraciones acerca del cambio que la ciudad experimenta, los cambios de los sujetos que la habitan y de lo incómodo y despreciable que esto resulta. Es así que las ideas y juicios de los personajes, que demuestran la inmundicia de las relaciones humanas, aparecen enmarcadas en una dinámica expresionista, de corte tanguero, en donde paisajes e ideas tiene una gran correspondencia con el universo del tango y por ende con la realidad anímica de los personajes. En tales circunstancias, la construcción literaria de los espacios en la novela evidencia la aprehensión de valoraciones populares alrededor de una serie de lugares característicos del tango. Esta operación consiste, como en las letras de tangos, en el establecimiento de un vínculo emocional entre espacio y sujeto, donde lo más común es ver al yo lírico tanguero habitar el cuarto de pensión, el bar, el cafetín, el prostíbulo, el arrabal.

Este ambiente que tango y novela comparten es el marco ambiental donde los personajes de Juntacadáveres lanzan sus juicios sobre la vida, sobre su propia existencia. Larsen/Junta oye desde su cuarto de pensión el bullicio de la calle, los "trajones" de la pensión, siente "la velocidad de la vida" y los ruidos extranjeros de motores, ruidos ajenos e incomprensibles, mientras entre murmullos e incomprensión sentencia: "Pueblo jodido, pueblo de ratas" (Onetti, Obras completas II, 427). Estos puntos de los personajes, que son recurrentes en la novela, se pueden contraponer a tangos como "Al mundo le falta un tornillo" (1933) de Enrique Cadícamo. Ante los primeros versos de la letra de Cadícamo "Todo el mundo está en la estufa,/Triste, amargao y sin garufa,/neurasténico y cortao...", la sentencia parece ser muy clara: el mundo está jodido. Las siguientes afirmaciones pueden ser aún más similares, pues la velocidad de la vida no es más que la sensación de vivir "de prepo" y de "apurao".

Ese sentir que al mundo le falta un tornillo es la incomprensión de lo que vive el hombre del tango. Esa incomprensión es tan clara en las palabras de Larsen/Junta que adquieren un carácter más socio-histórico en la sinécdoque del ruido de motores y en los ruidos extranjeros, aspecto que Onetti integra y que se enraízan a la lectura de una sociedad en pleno paroxismo social, a causa de los procesos de modernización. Justamente este panorama de alteraciones 
y arrebatos es fundamental tanto en la narrativa onettiana como en la lógica tanguera, pues el desencanto y el malestar son producto de algo perdido, de algo malogrado, frustrado, abortado. Este estado del sujeto del tango es divisado en los hombres y mujeres de Onetti; sujetos que a leguas se sienten y se leen desplazados, periféricos y marginales. Pero más que desplazados en un sentido espacial (siendo esto una realidad), son sujetos a los que se les arrebató el paraíso, un modo de vivir y un estado de sus almas. Adrían Gorelik identifica que tal expulsión del paraíso desemboca en una operación urbano-moral que el tango formuló en sus letras, siendo pues el "suburbio" sinónimo de lo bueno y perdido, y el "centro" un signo de lo inmoral (citado en Antúnez Olivera 8) 7 .

Tal aspecto es de suma importancia para la narrativa onettiana que logra acentuar esta valoración tanguera de ver en lo "impuro", en lo oscuro de un mundo marginal, virtudes como el ansia de la perfección, la capacidad de amar y la nobleza. Todas estas virtudes son el punto y motor cósmico de la insatisfacción de las mujeres y los hombres de Onetti, dado que a esa bronca, representativa del tango, es posible identificarla a través de la desilusión que causa la parcialidad de las empresas de los personajes. Pero lo que importa es que tanto el tango como los personajes de Onetti, marginales los dos, muestran esas riñas entre el bien y el mal que Lanza, el cronista sanmariano, logra identificar al final de los cien días de intensa "... lucha entre el oscurantismo y las luces" (Onetti, Obras completas II, 573).

\section{UN AMBIENTE DE TANGO CORROSIVO}

Y entre personajes "acompadrados" y descripciones que se asemejan a los tangos, se observa en la narración de la obra una cualidad lirica que estriba entre la expresión y la vitalidad de su referente. Hugo Verani, en Dos ensayos en torno a dos novelas de Onetti (1974), plantea que desde El pozo se avisaba un lenguaje que encarnaba las experiencias subjetivas de los personajes, a través de un lirismo capaz de ahondar en los estratos de la aventura humana,

\footnotetext{
Este sentimiento de pérdida ya ha sido reseñado en la novela que estudiamos. Rodrigo Cánovas en su artículo Volviendo la mirada hacia Juntacadáveres (1964), de Juan Carlos Onetti (2000) concluye que en Juntacadáveres, en los sujetos de la novela, hay un sentimiento de nostalgia y pérdida que se proyecta en una trascendencia negativa que desemboca en una unión teológica con la muerte, la locura, el absurdo y la dificultad.
} 
que quizá no fuesen posibles de aprehender desde fórmulas lógicas. A su vez, reseña Verani, tal interpretación lírica, iniciada en Latinoamérica por María Luisa Bombal y Onetti, corresponde, como sucede en "El infierno tan temido" (1962), a una suerte de un mundo lleno de huecos, ausencias y carencias que se movilizan entre lo disimulado y lo desconocido, tal cual como el silencio se manifiesta en la poesía (420-21).

En tal instancia y reconociendo la cualidad lirica que hay en las narraciones del escritor uruguayo, la inserción y el gran protagonismo de la atmósfera tanguera que se vive al leer una novela de Onetti deriva del conocimiento íntegro de un discurso, de un lenguaje que, al igual que el habla de sus personajes, logra abarcar su vitalidad, su subjetividad y sus situaciones objetivas. Y esto no es arbitrario si al leer las novelas de Onetti se encuentran, frecuentemente, frases cortas, algunas recortadas, llenas de supuestos, de gestos que el lector debe imaginar, como lo es en cierta medida ese constructo marginal que es el lunfardo, esa jerga criptica quintaesencia de las letras del tango. Además, la métrica de algunas de las descripciones y diálogos de Juntacadáveres ostentan una similitud tanguera: “-Más tranquilo, bebió un trago de cerveza y recitó-: La del Rosario y la Capital, la que te sacó de la cárcel, la que se fue y volvió, la que te tiró la muñeca arriba de la mesa del café. María Bonita. Para no acordarme (Onetti, Obras completas II, 411).

Tales precisiones ayudan a aterrizar y a sustentar la idea de la construcción de un espacio tanguero en la novela, donde personajes y lugares se funden para transmitir uno de los sentimientos más señalados en el tango y en la obra de Onetti: el desencanto. Así, desde las andanzas de Jorge Malabia, Díaz Grey, Larsen y las muchachas de la casa celeste, entre otros, se divisa una Santa María brumosa, nocturna o simple y llanamente oscura, siempre "húmeda y neblinosa" (Onetti, Obras completas II, 374). Esa Santa María de la cual el narrador siempre está hablando con una fuerza evocativa de su arquitectura, de sus casas y de su hermetismo: "Díaz Grey bajó desde Santa María hasta la Colonia, recorrió una L de calles asfaltadas y limpias, de casa blancas con tejas, con diminutas ventanas en el piso superior, defendidas y nunca abiertas..." (373). Justamente, Eduardo Tijeras (1963) expone que esta cualidad evocativa también aparece en el tango y desemboca, sea cual sea el objeto de evocación, en un asunto de burla o cuestionamiento de las condiciones de su clase social (318).

En ese caso no cabe duda de que esta reiteración de un paisaje semiurbano, como las casas de La Colonia, las de Santa María, los caminos de "yuyos en las junturas de las baldosas", la construcción de una arquitectura barrial, 
o de temprana ciudad, está erigida a partir de rasgos genéricos e intimistas, como los que anota el tango en sus letras. Y esto se reconoce en la novela de Onetti dado a un furor poético que dota de humanidad el paisaje. Así como "el barrio tiene el alma inquieta", las calles gastadas de Santa María son tenaces e imperfectas, (Onetti, Obras completas II, 513), como reconocimiento de un mundo hostil. A pesar de tal cualidad, las calles son la patria de los personajes onettianos, pues siempre se les ve en las estaciones de trenes, en las esquinas, en la plaza, en las calles. En Juntacadáveres estos sujetos se la pasan callejeando, de cuadra en cuadra y la narración de estos espacios siempre tiene el ánimo de quien las anda:

Tropezó con un banco bajo un árbol, metido en la oscuridad; se sentó y puso el bastón entre las rodillas. Estaba cansado como siempre, pero no aburrido, tampoco interesado. Un automóvil pasó enfurecido, invisible, junto al muelle; el ruido agitó un segundo el olor a pasto, de las plantas cónicas de los calderos (Onetti, Obras completas II, 438).

Esta relación entre el sujeto y la calle en la novela de Onetti es lo que Rafael Flores (1987) identifica en la poesía tanguera como "una especie de sacralización de la calle" donde el hombre de tango se forma (100), donde realmente se erige el ser onettiano y a su vez éste reinventa el espacio.

Otros espacios y ambientes tangueros predilectos de Onetti son la oscuridad de la mesa de un bar y la luz del farol. En primera instancia, esta obstinación por la soledad de una mesa que tienen los personajes de Onetti puede ser explicada en la actitud de un sujeto histórico ante su realidad. Precisamente Martínez González (2015) apunta que la soledad es la única salida de los personajes onettianos ante la incomunicación que tienen con el mundo, ya que "son individuos incompletos, incomunicados o escindidos por aquello que su propia naturaleza los condiciona a arrastrar" (162). Es por eso que un sujeto como Díaz Grey, condenado a ser un vocero de la lucidez y testigo de la vida sanmariana, modela la actitud de ese yo lírico del tango que ve la realidad desde la última mesa de un café o bar, tal como lo expresa el tango de Roberto Vidal, "Bar" (s.f.): 
(...) en la oscura mesa que pierde el rincón donde traza el vino de algún rostro su dolor.

Siempre el mismo cielo dibuja un farol... con las mismas sombras que no faltarán en las mismas calles que me llevarán cuando el cielo mismo me pierda en un bar..

Los barcos que se alejan ansían regresar buscando lo que dejan las calles sin final... apenas si molesta la voz del acordeón, sonata de los mares que muere en un rincón.

Las mesas no conversan, escuchan el rumor

de voces que se enfrentan detrás del mostrador...
Díaz Grey eligió el lugar más oscuro del bar del Plaza, lejos del mostrador ocupado por Marcos, sus amigos, las mujeres (Onetti, Obras completas II, 367).

El más Díaz Grey de los Díaz Grey está sentado a una mesa, solo, sin esperar a nadie. No es un café familiar, no es muy lujoso ni muy pobre, tiene ventanas sobre una avenida ancha y mal lavada (440)

Diaz Grey estaba tomando cerveza, solo, en la mesa junto a la ventana del bar del Plaza (557).

Esta soledad tan característica de los personajes onettianos, expuesta en el bar, en el café, en la pensión y en la calle, propone, desde la relación con el tango, una búsqueda de algo incierto, pero que llena de sentido la existencia de los personajes, búsqueda de ese conocimiento de sí mismo que los lleva inevitablemente a la soledad involuntaria: "soledad, que se cruza en mi camino". Y esta es una condición que el hombre del tango debe vivir a pesar de la "intensa amargura que triste me acompañan en mi soledad"10, porque si se revisan las letras de los tangos, es solo a través de la soledad que el yo lírico del tango logra alcanzar la contemplación, como "Silencio" (1932) de Alfredo Le Pera y Horacio Pettorossi. Y tal contemplación, tal vista panorámica, nacen de la soledad, esa misma que los personajes de Onetti acogen como "vocación profunda", tal como lo afirma Fernando Aínsa (1970). Esa vocación los hace participes de una honda sensibilidad que los castiga con la lucidez (47). 
Y esa soledad es la que hace que las farolas, símbolo de la urbe, sean las reflectoras que concentran e intensifican el objeto que percibe el ser del tango y en consecuencia a los personajes de Onetti. El halo del farol focaliza una realidad, emotiva o física, a la par que se convierte en uno de los lugares de tango con mayor ímpetu poético. Este imaginario explotado por el escritor uruguayo no es ajeno a sus intenciones narrativas como a su espíritu renovador, si se piensa que desde su trabajo en Marcha exhortaba por una literatura que lograra identificar a los montevideanos (Onetti, Obras completas $I I I, 8)^{11}$, una literatura que mirara alrededor suyo, que hablase de su realidad, del alma de la ciudad, una que lograra que Montevideo y sus habitantes aparecieran en ella $(15-16)^{12}$. En esa lógica, tomar elementos de una música y expresión cultural que por entonces había logrado aprehender mucho de la personalidad del sujeto rioplatense, el de las dos orillas, era vital en la composición de un sujeto que entre tantas facetas estaba constituido por la soledad y la frustración ${ }^{13}$.

En Juntacadáveres, como en los tangos, se muestra una mística del farol, una dialéctica entre el sujeto que percibe la realidad y se le releva a través de las luces suburbanas de la noche. Manuel Adet, en su columna La poesía del farol (10 de marzo de 2012) ${ }^{14}$, resume, en un comienzo contundente, que el farol es el todo del barrio: la esquina, la novia, la muerte, el malevo. El tango, dice Adet " $(. .$.$) crea y recrea el mito del farol", (...) "No hay tango sin nostalgia,$ sin amores perdidos y sin farol”. En tales circunstancias es muy común ver a los sujetos onettianos ligados vital e íntimamente con este espacio. Dada la realidad cronotópica de los personajes, como plantea Bajtín ${ }^{15}$, esta dialéctica

11 En "Una voz que no ha sonado", Marcha, 30 de junio de 1939, por Periquito el Aguador.

12 En Literatura Nuestra, Marcha, 25 de agosto de 1939, por Periquito el Aguador.

13 Justamente Montero Aroca, en su libro Historia del tango Canción (1917-1967. Los años de oro) (2013), afirma que para los años cuarenta la voz de Discépolo trasmutó del portavoz de la sociedad enferma a la emisaria del hombre solo y frustrado, “... para el que la vida ha perdido el sentido que en la juventud creía que debía tener” (186).

14 El Litoral, diario argentino.

15 El fundamento de Bajtín sobre este punto parte de las consideraciones que Kant, en su Estética trascendental, en la Crítica de la razón pura (1781), tiene sobre el tiempo y el espacio. Siendo estas nociones formas indispensable para todo conocimiento, Bajtín rescata que tiempo y espacio no son meras cuestiones sensibles, también las reconoce como formas auténticas de una realidad material que inciden en el proceso creativo (artístico) y de conocimiento de los sujetos $(1989$, p. 238). 
(sujeto/farol) supone una subjetivación de la realidad, la proyección de su experiencia vital y los límites de su expresión. Es así que los cuadros más fuertes de la realidad sanmariana son delimitados por el farol, como el de las mujeres de la casa celeste luego de su incómodo y hostigante paseo por la moralista Santa María (Onetti 2007, 424) y la percepción de los odios y "las conspiraciones inmaduras en los faroles de las calles", vistas por María Bonita (426); todos y cada uno de estos cuadros, entre varios, impregnados por las voliciones de sus testigos.

\section{CONCLUSIÓN}

La relación que la obra de Onetti guarda con el tango es ineludible. Las condiciones de producción de la obra del autor uruguayo, unidas a la tradición naturalista y criollista del Uruguay, fueron un espacio propicio para ser, más que ruptura, puente entre una literatura que ya contaba con una línea social de corte crítico, pero que su referente antropológico estaba desactualizado y gastado. Al mismo tiempo, las condiciones del campo literario uruguayo permitieron revalorar las condiciones de un tipo de sujeto que se debatía entre lo antiguo y lo nuevo, aspecto tan importante al tratar de comprender al sujeto de la actualidad montevideana y latinoamericana de finales del XIX y principios de XX. En tales circunstancias y dada la propuesta estética onettiana en Juntacadáveres, tanto el tema como los sujetos están ligados a un universo capaz de conciliar lo antiguo y lo nuevo en formas y sentidos que construyen la idiosincrasia de una época, esta misma que se consolidó como medio y respuesta a los procesos de modernización en el río de la Plata a través del tango.

La consolidación de esta música como producto popular y de masas mostró desde la mezcla de distintas manifestaciones trasatlánticas una capacidad de contener el sentimiento y valoraciones de una época de cambios, esas que permearon a su vez la literatura -la poesía, el teatro (el sainete) la novela- la cultura, la política, la religión, etc. Entre formas evocativas, de convenciones propias y una crítica a los distintos temas de su realidad, el tango logró advertir, a través de su nostalgia, más que su apego al pasado, sus posibilidades presentes y futuras. En ese sentido, la obra de Juan Carlos Onetti, especialmente la obra objeto de este análisis -Juntacadáveres- logra desplegar, desde su fábula, una diversidad temática que fue interés del tango, a su vez que toma íconos del discurso tanguero como valoraciones colectivas 
alrededor de espacios y conductas de sus protagonistas, sirviéndose de un lenguaje capaz de ahondar en la subjetividad de sus personajes y en la objetividad de sus situaciones. Así, el valor estético que posee Juntacadáveres con respecto al tango consiste en una revalorización, desde situaciones aparentemente cotidianas, de la trascendencia cultural, existencial y literaria del universo del tango como referente popular, incidente en las prácticas de una comunidad como la ficticia Santa María, imagen y semejanza de tantas ciudades rioplatenses o latinoamericanas.

\section{BIBLIOGRAFÍA}

Adet, Manuel. "La poesía del farol”. El Litoral. 10 mar. 2012. Web <http://www.ellitoral.com/ index.php/diarios/2012/03/10/escenariosysociedad/SOCI-03.html

Aínsa, Fernando. Las trampas de Onetti. Montevideo: Alfa, 1970.

"Raíces populares y cultura de masas en la nueva narrativa hispanoamericana". América, Cahiers du CRICCAL, no. 1, vol. 25 (2000): 7-16.

Antúnez Olivera, Rocío. "E1 Buenos Aires literario de Juan Carlos Onetti”. Revista Casa del Tiempo. Web. Mayo de 2014 <http://www.uam.mx/difusion/revista/mayo2004/antunez.pdf

Anaya López, Alij Aquetza. "Lo popular urbano y sus expresiones en la narrativa breve: oralidad y abyección en Ni farra ni vieja ni sombreros de charro de Juan Maya". Nóesis. Revista de Ciencias Sociales y Humanidades, № 40 (2011): 168-191.

Aroca, Juan Manuel. Historia del tango canción. (1917-1967. Los años de oro). Valencia: Tirant Humanidades, 2013.

Bajtín, Mijaíl Mijáilovich. Estética de la novela. Madrid: Taurus, 1989.

Borges, Jorge Luis. El tango. Cuatro conferencias. Colombia: Lumen, Penguin Random House Grupo Editorial, 2016.

Cánovas, Rodrigo. "Volviendo la mirada hacia "Juntacadáveres" (1964)", de Juan Carlos Onetti. Universidad de Chile, Revista Chilena de Literatura 56 (2000): 33-52.

Carretero, Andrés. M. Tango: testigo social. Buenos Aires: Peña Lillo, Ediciones Continente, 1999.

Chavarri, Raúl. “Juntacadáveres”. Madrid: Cuadernos Hispanoamericanos 292/294 (1974): 527-534.

Del Priore, Oscar. Cien tangos fundamentales. Buenos Aires: Aguilar, 2011.

Deredita, John. El lenguaje de la desintegración: Notas sobre "El astillero”. Montevideo: Biblioteca Marcha, 1973.

Flores, Rafael. "Los letristas de tango y su ambiente”. Madrid: Cuadernos Hispanoamericanos, 445 (1987): 99-105.

Gadea, Carlos A. "Tango y Desencanto de la Modernidad". Revista Contratiempo, Arte, pensamiento y política 3 (2011): 69-74. 
Gobello, José. Crónica general del tango. Buenos Aires: Editorial Fraterna, 1980.

Martínez González, V. H. "El humanismo radical de Juan Carlos Onetti". Revista de El Colegio de San Luis 5. Vol. 9 (2015): 160-179.

Mattalia, S. La figura en el tapiz: teoría y práctica narrativa en Juan Carlos Onetti. Vol. 137. Tamesis, 1990.

Motato, Hernando. "La presencia del tango en «El túnel»". La Palabra 19 (2011): 17-24.

Onetti, Juan Carlos. Obras completas II. Juan Carlos Onetti. Novelas II (1959-1993). España: Galaxia Gutemberg, Círculo de Lectores, 2007.

Obras Completas III. Juan Carlos Onetti. Cuentos, artículos y misceláneas. España: Galaxia Gutemberg, Círculo de Lectores, 2009.

Premat, Julio. "Cuando nombre, entonces relato". Río de la Plata 25 (2001): 193-202.

Rama, Ángel. "Las dos vanguardias latinoamericanas". Moldoror, Revista de la ciudad de Montevideo 9, 1973.

Sábato, Ernesto. Tango: discusión y clave. Buenos Aires: Editorial Losada, 2005.

Savigliano, Marta Elena. "Malevos llorones y percantas retobadas: el tango como espectáculo de razas, clases e imperialismo". Relaciones de la Sociedad Argentina de Antropología 19, 1994.

Tijeras, Eduardo. "Un ambiente de tango trascendido". Cuadernos Hispanoamericanos 163/164 (1963): 314-319.

Verani, Hugo. J. "Dos ensayos en torno a dos novelas de Onetti”. Madrid. Cuadernos Hispanoamericanos 292/294 (1974): 408-464.

"Un diálogo de artistas fracasados: Juntacadáveres". Centro de Investigaciones Lingüistico-Literarias, Universidad Veracruzana. Texto Crítico, julio-diciembre, 1980. 165-170. 